\title{
ALINEAMIENTO, INDIFERENCIA Y FORMAS DE RESISTENCIA CIUDADANA ANTE EL NUEVO ESTADO FRANQUISTA EN LOS PRIMEROS AÑOS DEL TERROR, 1936-1945.
}

\author{
MIGUEL ÁNGEL MELERO VARGAS (UMA, FAP) \\ Universidad de Málaga, Fundación Alfonso Perales \\ melerovargas@hotmail.com
}

\begin{abstract}
Resumen:
Los más recientes análisis sobre la actitud de la población española de los años Treinta y Cuarenta del siglo pasado ante el establecimiento del franquismo, ha permitido el descubrimiento de toda una gama de comportamientos y situaciones que superan en mucho el simplismo de la dicotomía entre vencedores y vencidos de la guerra, descartando por ello patrones de comportamiento inamovibles, y permitiendo de paso graduar también la intensidad y efectividad en que se consigue o fracasa una captación de apoyos al Régimen. En este sentido el texto que sigue pretende contribuir a enriquecer el debate establecido en torno a este campo de conocimiento dentro del franquismo, para conocer de forma más certera los mecanismos de funcionamiento del Régimen, como su proyección sobre la vida cotidiana de la sociedad española de estos primeros años.
\end{abstract}

Palabras clave:

Franquismo - Actitudes Ciudadanas - Andalucía - Antequera

\begin{abstract}
:
The most recent analysis of the attitude of the Spanish population in the thirties and forties of the last century before the establishment of francoism, has enabled the discovery of a range of behaviors and situations that far exceed the simplistic dichotomy between winners and losers of the war, thus discarding entrenched patterns of behavior, and allowing passage also grade the intensity and effectiveness that is achieved or fails again lobbying Franco regime. In this regard the following text aims to contribute to enrich the debate established on this field of knowledge within francoism, to hear more accurate way the mechanisms of the scheme, as its projection on the daily life of the Spanish Society these early years.
\end{abstract}

Keywords:

Francoism - Civil Attitudes - Andalusia - Antequera 


\title{
ALINEAMIENTO, INDIFERENCIA Y FORMAS DE RESISTENCIA CIUDADANA ANTE EL NUEVO ESTADO FRANQUISTA EN LOS PRIMEROS AÑOS DEL TERROR, 1936-1945.
}

\author{
MIGUEL ÁNGEL MELERO VARGAS (UMA, FAP)
}

melerovargas@hotmail.com

\section{Introducción:}

\section{Del simplismo franquista de las dos comunidades al no solo blanco/negro}

Tras el final de la guerra civil española, la distinción entre entusiastas y enemigos de la verdadera España constituyó la base del discurso legitimador y justificativo empleado por los artífices del Nuevo Estado, tanto para explicar las razones de su sublevación como las que sustentaron su proyecto de control social a través de la violencia política.

Constituía la base de su proyecto, dicotómico y estereotipado, de las dos comunidades, concentrando en torno a valores de Nación, Patria, Tradición y Fe Católica a una parte de la población, mientras que desarraigaba a otra considerada "no-afecta". ${ }^{\text {Un }}$ proceso de cohesión/exclusión, de identificación de protagonistas por el que discurrirían los cauces establecidos entre el Régimen y sus dos comunidades, la triunfal y la sometida, para regular la relación entre ambos. Sin embargo aparecerían matices que demuestran que no se trató de una estrategia exitosa en su totalidad, pues proliferaron actitudes entre la población que no fueron las planeadas y estancas de afección y rechazo, sino también otras, variables y rotatorias, que no mostraron cercanía con ninguno de los polos opuestos, demostrando que las actitudes ciudadanas ante el Régimen franquista, ya desde el primer momento de su implantación, e incluso antes, a medida que se gestaba la ocupación militar de territorio leal a la República y se implantaba el Terror como principal seña identificativa, no se establecieron sobre un tapiz de blanco y negro, sino que por el contrario ofrecieron toda una "cromática" de comportamientos que, aún a día de hoy, y ya con numerosos trabajos específicos para el caso español, resulta muy complicado perfilar.

De sobra es conocida ya la valiosa herencia proporcionada por los trabajos que desde Alemania, Francia o Italia, centraron sus análisis en las dictaduras nazi y fascista, de las que destaca la definitiva aportación de la escuela historiográfica sobre la vida cotidiana alemana, la Alltagsgeschichte, y que habían comenzado hace ya casi tres décadas a poner de realce el complejo abanico de actitudes de la población ante el nazismo, eliminando las simplicidades dicotómicas de víctimas y verdugos, o coautores y resistentes ${ }^{2}$, y dando ya una importancia capital al papel de las

\footnotetext{
${ }^{1}$ General Mola. Instrucción Reservada N ${ }^{\circ}$ 1, Base $5^{\text {a }} .25$ de abril de 1936, General Goded. Bando de declaración del Estado de Guerra en las Islas Baleares. Artículo $3^{\circ}$ y General Varela. Bando de Guerra en Antequera. 13 de agosto de 1936.

${ }^{2}$ De la misma forma la superación de este simplismo dicotómico ya se llevó a cabo para el caso del fascismo italiano a través del historiador Renzo de Felice, cuando hace más de tres décadas señaló que, a pesar de que buena parte del secreto de la perdurabilidad de los regímenes totalitarios residía en el empleo de la represión y la violencia, solo pudieron mantenerse en la medida en que gozaron del apoyo y consentimiento de una importante parte de la población, y que debía ir más allá del estrecho círculo de poderes políticos, económicos y sociales dominantes. Felice, Renzo de, Mussolini il duce. Lo Stato totalitario, 1936-1940, Turín, Einaudi, 1981, p. 156 y ss.
} 
zonas grises, con una amalgama de comportamientos que permitían la entrada y asimilación de tipologías como consenso activo, acomodación, no-conformidad, aprobación, rechazo o aceptación, ${ }^{3}$ como la bifurcación establecida entre la Aceptación -dividida a su vez en Adhesión, Apoyo y Resignación- y la Distancia -con una categorización que fluctuaba entre la Desviación, la Disidencia y la Oposición-. ${ }^{4}$

Comenzaba pues a vislumbrarse que los historiadores dedicados al estudio de esta parcela dentro del franquismo no abordaban un objeto de análisis sencillo, sino por el contrario abierto y susceptible a una enorme cantidad de matices que nos mostrarían cómo "en el terreno de las actitudes políticas bajo la dictadura, la complejidad, las paradojas, las incongruencias y los contrasentidos son lo que más abundan, y cualquier determinismo simplificador no tiene cabida". ${ }^{5}$

Efectivamente la tipificación entre adictos y desafectos resultaba a todas luces insuficiente, y la prevalencia de los comportamientos grises, de indiferencia, aprobación, pasividad e incluso otros que implicaban disidencia o resistencias de perfil bajo, sobresaldrían necesariamente por encima de otros más categóricos, inamovibles y polarizados.

Esta postura, defendida entre otros por el historiador Jordi Font en base a sus estudios sobre las actitudes políticas de la clase media rural gerundense en las dos primeras décadas del franquismo, ya plantea uno de los principales rasgos definitorios del comportamiento ciudadano ante el Nuevo Estado: la ambigüedad en el sentido de la multiplicidad de actuaciones ciudadanas, oscilantes y negociables. Una tesis en torno a la cual girarían los principales estudios -de los que nos haremos eco en este texto- y que, obteniendo un brillante aprovechamiento, fundamentalmente del modelo historiográfico cotidiano alemán, han reflexionado desde hace aproximadamente tres lustros y con creciente empeño y acierto sobre la actitud de la población española ante el franquismo, sobre todo en los primeros años de la posguerra.

Todos coincidirían en la necesidad de elaborar cuadros de identificación, tipificación y estratificación de comportamientos, como de las situaciones derivadas de éstos, en base a variables como el grado de recuerdo del efecto traumático de la guerra, el alcance de la represión y la aplicación de la violencia, el rédito obtenido en base al apoyo, o el contexto internacional; y desde luego la efectividad del discurso legitimador franquista para el establecimiento del Régimen como para la justificación de su violencia extrema. ${ }^{6}$

En este sentido, el objetivo de este texto reside en contribuir, a través de nuestra aportación a partir de ejemplos desde nuestro ámbito principal de estudio, la comarca andaluza de Antequera ${ }^{7}$, al enriquecimiento de los diferentes debates establecidos en base a un análisis en perspectiva comparada de los estudios realizados por los principales especialistas en este campo de conocimiento dentro del franquismo, para conocer de forma más certera los mecanismos de funcionamiento del Régimen, como su proyección sobre la vida cotidiana de la sociedad española de estos primeros años.

\footnotetext{
${ }^{3}$ Peuckert, Detlev, Inside Nazi Germany. Conformity, Opposition and Racism in Everyday Life, London, Penguin, 1987.

${ }^{4}$ Burrin, Philippe, Francia bajo la ocupación nazi, 1940-1944, Barcelona, Paidós, 2004, 197-198.

${ }^{5}$ Font, Jordi, “-Nosotros no nos cuidábamos de la política-. Fuentes orales y actitudes políticas en el franquismo. El ejemplo de una zona rural, 1939-1959”, Historia Social, 49, 2004, pp. 51 y 66.

${ }^{6}$ Así por ejemplo, el denominado como Proyecto Valencia. Saz, Ismael, Fascismo y franquismo, Valencia, Publicacions de la Universitat de València, 2004, pp. 185-186. Una obra que supone, sobre todo en los capítulos en que se hace referencia a nuestro tema de estudio sobre las actitudes ciudadanas ante el Régimen, una ampliación y mejora de aquellos que ya aparecieron, cinco años antes en Gómez, Alberto y Saz, Ismael (eds.), El franquismo en V alencia: formas de vida y actitudes sociales en la posguerra, Valencia, Episteme, 1999.

7 Situada en el norte de la provincia andaluza de Málaga, y limítrofe con las de Córdoba y Sevilla, la comarca de Antequera fue ocupada en su totalidad por las tropas sublevadas entre agosto de 1936 y febrero de 1937. Su población actual ronda los 65.000 habitantes.
} 


\section{Cromática de las actitudes ante el franquismo}

\section{Consenso reaccionario y Consentimiento activo}

Los diferentes estudios que recogen las reacciones ciudadanas ante el Nuevo Estado franquista establecen como incontestable una categoría que recoge comportamientos de adhesión sin condiciones, inquebrantable, por convicción, y que implica una total aceptación del discurso justificativo y legitimador del Régimen, mostrando con él un pleno alineamiento y aquiescencia, aunque ello no supusiera necesariamente su participación destacada en cuadros políticos o puestos de responsabilidad.

Los trabajos, entre otros, de Jordi Font, Ismael Saz, Francisco Sevillano, Francisco Cobo, o más recientemente de Claudio Hernández, Óscar Rodríguez o Ana Cabana así lo defienden, situando además estos dos últimos autores la adhesión inquebrantable como una sub-categoría dentro de otra principal de Consentimiento en su grado máximo; una "colaboración providencia" que implica una adhesión a partir de la plena convicción ${ }^{8}$.

Una categorización que obviamente aceptamos, sobre todo en lo que supone su actitud ante el franquismo tras la guerra, pero que a su vez nos lleva a reflexionar sobre la idoneidad de distinguir, dentro de ésta, al colectivo compuesto por aquellos que no solo abrazaron este Consentimiento activo desde los primeros momentos de la sublevación, sino que formaron parte antes de la guerra del proceso conspirativo que dio lugar a la misma; los miembros de un "consenso reaccionario" en el que tuvieron cabida una parte muy importante del Ejército, la gran mayoría de la Iglesia, Falange, el conservadurismo político -desde los partidos tradicionales monárquicos a otros de reciente creación y progresivamente fascistizados- o las oligarquías rurales y urbanas.

Un claro ejemplo lo encontramos en Antequera, donde Juan Becerra García, barbero afiliado a Falange desde 1934 y Jefe Local en la ciudad desde mayo de 1935, se dirige a finales del invierno de 1936, con motivo de la proximidad de los comicios de febrero, a los simpatizantes de la organización, señalando que:

"la gravedad de los momentos actuales, acentuada por la proximidad de las elecciones municipales, exige una actuación enérgica y decidida, en una lucha tenaz y heroica en defensa de nuestra civilización occidental y cristiana, amenazada de muerte por la revolución marxista y sus lacayos". ${ }^{10}$

La posterior detención de Becerra se acompañaría del señalamiento de varios miembros de algunas de las principales familias propietarias agrícolas e industriales de la ciudad, a su vez miembros destacados de partidos derechistas, como sustentadores económicos de la organización -los informes señalan asimismo que fueron registradas sus propiedades, encontrando armamento y propaganda fascista- siendo situadas además sus reuniones en los conventos de La Trinidad y Capuchinos, y manifestando incluso varios alumnos del colegio seráfico de este último que los sótanos del convento contenían abundante armamento.

Oteaba por tanto un entramado político y económico, en el que el sector derechista de la ciudad, valiéndose de la Iglesia como encubridora y de este grupo fascista como brazo ejecutor, se preparaba en vistas a una actuación contra el régimen republicano establecido, lo que tendría

${ }^{8}$ Cabana, Ana, "De imposible consenso. Actitudes de consentimiento hacia el Franquismo en el mundo rural (19401960)", Historia Social, 71, 2011, pp. 89-106.

9 Cobo, Francisco (coord.), La represión franquista en Andalucía. Balance bistoriográfico, perspectivas teóricas y análisis de resultado, Sevilla, Centro de Estudios Andaluces, 2012, p. 17.

${ }^{10}$ Sucesos de carácter político-social. Antequera, 1936. (Archivo del Gobierno Civil de Málaga) 
consecuencias inmediatas en la proliferación de sucesos conflictivos durante los meses de Frente Popular, como en la acentuada violencia desarrollada en la retaguardia republicana antequerana. ${ }^{11}$

En todo caso, a todos ellos se atribuía una clara afinidad ideológica con los preceptos de la Nueva España, sobre todo en lo que supone su marcado anti-republicanismo, como el miedo a la pérdida de un privilegiado estatus forjado a base de siglos, como consecuencia de las medidas reformistas republicanas. Un miedo que no tardaría en mutar, de forma paralela a la progresiva ocupación de territorio leal a la República, en una actitud compensatoria de denuncia y señalamiento sobre los vencidos, fundamentalmente como materialización de la venganza por el sufrimiento previo de la etapa republicana o su retaguardia ya en la guerra ${ }^{12}$, y que se traduciría en un decidido y fundamental respaldo económico y material, logístico, e incluso moral y anímico, cuando el fracaso de la sublevación la transformara en guerra civil, y hasta la definitiva victoria militar rebelde.

Así, no era de extrañar por ejemplo que a mediados de agosto de 1936, recién ocupada Antequera, sesenta de las familias más acaudaladas de la ciudad avalaran un crédito de 300.000 mil pesetas con destino al Ejército sublevado en Andalucía, como que buena parte de estas mismas familias pusieran sus hogares a disposición de éste a través de un servicio de alojamiento de militares que acogiera a la oficialidad de las fuerzas que tenían a Antequera como centro de concentración y distribuidor de tropas a otros frentes de combate; tampoco resultaba raro que sus mujeres - madres, hermanas, hijas y viudas- abandonaran el confinamiento al que el Régimen las destinaba, para convertirse en la "caricia de la retaguardia"13 , a través de labores patrióticas de asistencia hospitalaria, como de soporte material y anímico a través de las figuras de la Madrina de Guerra y la Madrina de Cama. ${ }^{14}$

Entre ellos también pudieron tener cabida los denominados como Nuevos Hombres, aquellos con un bagaje político nulo o muy escaso, pero con una nueva cultura política forjada en la guerra, y que a través de su filiación falangista irían ocupando los nuevos puestos de responsabilidad en las diferentes administraciones, en detrimento de los representantes de esa vieja política anterior a la República.

11 Melero, Miguel Ángel, De la Esperanza al Sometimiento. Frente Popular, guerra civil y primer Franquismo en una ciudad andaluza: el caso de Antequera, Málaga, Tesis doctoral, 2013.

12 Parejo, José Antonio, "Fascismo rural, control social y colaboración ciudadana”, Historia Social, 71, 2011, 143-159, y en cuya página 144 se ofrece bibliografía sobre la participación ciudadana en la represión en otros casos europeos. Anderson, Peter y Arco, Miguel Ángel del, "Lidiando con el oscuro pasado de España”, en Anderson, Peter y Arco, Miguel Ángel del (coords.), Lidiando con el pasado. Represión y memoria de la guerra civil y el franquismo, Granada, Comares, 2014, pp. 11-12. Una delación como venganza por el sufrimiento anterior no entenderá de sexos, como bien se señala en Cobo, Francisco y Ortega, Teresa María, "Franquismo y represión femenina...”, art. cit., p. 75.

13 Así se define la labor de la mujer en el cuidado de los convalecientes en los hospitales antequeranos durante la guerra, en El Sol de Antequera, Antequera, 17 de octubre de 1937, p. 6.

${ }^{14}$ Las figuras de la madrina de guerra como la madrina de cama representan dos de las principales figuras que reflejan el papel de la mujer en la retaguardia sublevada en su relación con el frente: la asistencia económica, moral y anímica a los combatientes; en el primero de los casos a través de una relación epistolar ideada -ya de hecho empleada en la Primera Guerra Mundial- para combatir la soledad del soldado en la trinchera, pero de paso con un claro interés material, por convertirse éstas en suministradoras de ropa de abrigo, prensa y revistas, novelas, tabaco o vino, para sus "ahijados", mientras que en el segundo a partir de una relación similar, pero de forma física y directa, acudiendo a los diferentes hospitales de la ciudad en que se encontraban convalecientes combatientes enfermos o heridos. Estas dos figuras que representan lo que desde algún medio local se las denominó como la "caricia de la retaguardia", como el resto de formas de participación y contribución han sido analizadas profusamente en Melero, Miguel Ángel, "Tomando la palabra... y empuñando el fusil: la participación ciudadana en la guerra civil. La ocupación sublevada y la represión. Un caso andaluz, Antequera”, IV Encuentro de Jóvenes Investigadores en Historia Contemporánea, Valencia, 10-13 de septiembre de 2013, así como en ÍD; “Vecinos armados y 'parásitos' grises: una visión asimétrica de la participación ciudadana en la Guerra Civil española. Milicias populares y milicias fascistas entre en el frente y la retaguardia", en Macías, Daniel y Puell, Fernando (eds.), David contra Goliat: guerra y asimetría en la edad contemporánea, Madrid, Instituto Universitario General Gutiérrez Mellado, 2014, pp. 173-199. 
La estrategia de cohesión franquista llevó igualmente a que el encuadramiento en grupos paramilitares constituyera una parte esencial de esta actitud de alineamiento con el Régimen; una participación física y directa, muy involucrativa, proporcionando a sus miembros un rango más en el proceso de participación ciudadana a través de su colaboración como agentes de la represión, y en la construcción de un estado para-policial y auto-vigilado. ${ }^{15}$

Pero el apoyo, aunque incontestable y sin fisuras, no fue idílico en el sentido de que no solo se forjó bajo principios de afinidad discursiva, sino que respondía también un marcado interés personal como motor para la movilización a favor del Régimen.

Así se establecía una "colaboración conveniencia", ${ }^{16}$ de consentimiento pleno en base a los réditos que pudieran granjearse, y donde por tanto se encuadran aquellos que, por sus servicios al Régimen, tuvieron la oportunidad de mejorar ostensiblemente su situación económica, bien a través de subvenciones, ayudas o ventajas a la hora de acceder a un puesto de trabajo -voluntarios en fuerzas paramilitares y combatientes, ex combatientes o mutilados-, como de aquellos que se lucraron con la miseria generalizada, haciendo un uso fraudulento de una ya de por sí capciosa política autárquica franquista, y de sus derivaciones: racionamiento, mercado negro, estraperlo, ${ }^{17}$ encontrando siempre una actitud permisiva y condescendiente de un Régimen violento como corrupto.

Pero la asimilación del discurso franquista implicaba además una clara correlación con una postura de abominación de la violencia desarrollada en la retaguardia republicana, y los comportamientos revolucionarios y exaltados que en ésta derivaron hacia acciones de violencia extrema física y material, fundamentalmente iconoclasta, generaron el rechazo -y su consiguiente apoyo al Régimen- de colectivos que a priori podían mostrarse como más tenues e indecisos. Y es que no solo oligarquías, Iglesia, parte del Ejército, falangistas, o la denominada como "gente de orden" 18 , formaron parte de ese apoyo incondicional, sino también pequeños y medianos propietarios, modestos empresarios y humildes comerciantes, clases medias y otros colectivos que se sintieron atacados en sus intereses económicos, o en sus principios morales y religiosos.

El estatus social -más que el grupo social- resultó en buena parte el instrumento cohesor en el apoyo sin fisuras al franquismo; tanto de aquellos que tuvieron miedo de perderlo, como de los que buscaron alcanzar y acomodar el suyo ante el futuro que se mostraba.

\section{Una parada necesaria: De nuevo ¿Consentimiento o consenso?}

Pero, ¿eran estas actitudes de consenso o consentimiento? En un debate ya de larga duración, algunos especialistas, como en el caso más reciente el profesor Julián Sanz, establecen como inadecuada la expresión consenso para referirse a la conformación de los apoyos a la Dictadura, por estimar que "resulta de imposible aplicación a un contexto dictatorial marcado por una violenta represión". ${ }^{19}$

En una línea muy similar, y casi coetáneamente, la profesora Ana Cabana, en su completo estudio sobre las actitudes ante el franquismo de los miembros del rural gallego durante los dos primeros decenios del Régimen, insistía en que su uso resultaba inapropiado, por considerar que solo podía

\footnotetext{
15 Un aspecto que ya se apuntaba en Arco, Miguel Ángel del, "El secreto del consenso en el régimen franquista: cultura de la victoria, represión y hambre”, Ayer, 76, 2009, pp. 245-268.

${ }^{16}$ Cabana, Ana, "De imposible consenso...", art. cit., pp. 89-106.

17 Arco, Miguel Ángel del, "La lucha continúa: represión y resistencia cotidiana en la España de postguerra”, en Anderson, Peter y Arco, Miguel Ángel del (eds.), Lidiando con el pasado..., op. cit., p. 188.

${ }^{18}$ Cabana, Ana, Xente de Orde. Consentimiento cara ao Franquismo en Galicia, A Coruña, Tresctres, 2010.

${ }^{19}$ Sanz, Julián, "Los hombres de Franco: sobre los cuadros locales de la Dictadura”, en ARCO, Miguel Ángel del et alii, No solo miedo. Actitudes políticas y opinión popular bajo la dictadura franquista. Granada, Comares, 2013, p. 84.
} 
tener cabida en relaciones de población-Estado establecidas en sistemas democráticos, y no en aquellos que no permiten muestras de Disconformidad. ${ }^{20}$

Lo mismo había defendido Ismael Saz años antes, al considerar que las reservas de una parte de la población, o las actitudes de resistencia, aversión y oposición, impedían el poder hablar de consenso. ${ }^{21}$

Solo el profesor Francisco Sevillano Calero, en uno de los primeros trabajos en que se abordaron como tema central las actitudes ciudadanas ante el franquismo, parecía haber mantenido el empleo de este término, si bien circunscribiendo su campo de actuación al espacio ocupado por los vencedores, como de otros movidos entre la aceptación no reditual como la interesada, como los voluntarios en el Ejército sublevado, mutilados, cautivos, combatientes y excombatientes, que recibieron empleos y tratos de favor y subvenciones, o de aquellos que se lucraron con el mercado negro, ante la mencionada complacencia de las autoridades franquistas.

Así pues para Sevillano, factores como la cultura política que llevó a la sublevación, la elaboración del discurso legitimador, la política de prebendas, intereses y corrupción, o la exacerbada represión en sí misma, fueron aspectos forjadores de un consenso con una parte de la población, y que contrastó con el miedo paralizador, desmovilizador, anulador de la identidad política, que evolucionó hacia la apatía, el acomodamiento y el acatamiento ante la necesidad de sobrevivir, de otra parte. ${ }^{22}$

Esta idea es igualmente compartida por los profesores Carme Molinero y Pere Ysàs, que defendieron la idoneidad de no-sobredimensionamiento del concepto de consenso, afirmando además que en las actitudes hacia el franquismo debían influir necesariamente aspectos como los sectores sociales con los que éste se estableciera, las peculiaridades nacionales o regionales, o el contexto histórico en que se analizaran esas actitudes. ${ }^{23}$

Nuestra opinión, sustentada en buena parte por la etapa de la dictadura en torno a la que gira este texto -los primeros años desde el final de la guerra civil- es más cercana a estas últimas tesis que a las del resto de visiones sobre la pertinencia o no en el empleo del consenso, por estimar que la clave debe residir efectivamente en un correcto dimensionamiento del mismo, como en la adecuada delimitación de aquellos con los que se establece, o de las diferentes condiciones que permiten que la "negociación", permítase la expresión, fructifique.

Es decir, si por consenso se considera "el acuerdo producido por consentimiento entre todos los miembros de un grupo o entre varios grupos" ${ }^{24}$, defendemos que la clave resida en una concepción menos abarcadora del término, más concreta y más acotada a un grupo, el de aquellos que, o bien formaron parte del consenso reaccionario que facilitó la sublevación, o el de los que, a posteriori, mostraron una aquiescencia, un alineamiento y un apoyo sin fisuras al Régimen, y en los que sí existe una actitud activa, positiva y voluntaria, haciendo innecesario el empleo de la represión y el control social, e incluso ni tan siquiera mecanismos de negociación, pues entre ellos y el Estado la armonía y la cohesión habían sido contrastadas.

Por ello debemos, por ejemplo, descartar obviamente un consenso entre Nuevo Estado y vencidos, pues los mecanismos de interacción entre ellos fueron engrasados con posturas de violencia/sometimiento, pero nunca por supuesto entre el Poder y los integrantes de la casta de vencedores, situándolo en el grado más alto de un consentimiento activo, el providencial.

\footnotetext{
${ }^{20}$ Cabana, Ana, “De imposible consenso...", art. cit., pp. 91-92.

${ }^{21}$ Saz, Ismael, Fascismo y franquismo..., op. cit., p. 181.

22 Sevillano, Francisco, "Consenso y violencia en el "nuevo estado" franquista: historia de las actitudes cotidianas, Historia Social, 46, 2003, p. 169.

${ }_{23}$ Molinero, Carme e Ysàs, Pere, El règim franquista. Feixisme, modernització i consens, Vic, Eumo, 1992.

${ }^{24}$ Lema.rae.es/drae/?val=consenso. Consulta realizada el 25 de agosto de 2014.
} 
Y esta reflexión nos lleva a otra cuya resolución no nos resulta menos preocupante. ¿'Tiene el Régimen entre sus objetivos la búsqueda de un consenso activo y entusiasta entre la población, o por el contrario mostró su conformidad en un consentimiento más o menos pasivo de ésta?

Borja de Riquer, en su estudio sobre las actitudes políticas de la población catalana en la primera década de vida del Régimen, sostiene que el franquismo fue incapaz de "generar una adhesión activa y entusiasta, aunque sí una notable pasividad política social", o lo que es lo mismo, "aspiraba a ganarse el consentimiento y apoyo de la inmensa mayoría de la población pero no buscó la articulación de un consenso activo y entusiasta". ${ }^{25}$

Una afirmación que se sustenta sobre unos principios de desmovilización y despolitización, y que ya reflejara a su vez Ismael $\mathrm{Saz}^{26}$, al afirmar que el Régimen "aspira a ganarse el consentimiento...pero no buscó la articulación de un consenso activo".

Nuestra percepción sin embargo nos lleva a disentir sobre estas afirmaciones de Saz y De Riquer ya que, si bien es cierto que el Nuevo Estado alcanzó buena parte de sus objetivos en base a la pasividad política o la desmovilización, o a la resignación y la aceptación pasiva -fundamentales entre otras cosas para desactivar acciones de resistencia más organizada y pública, y por ello más susceptibles de desestabilizar al Régimen- su discurso cohesionador de una comunidad de vencedores, su mastodóntica actividad propagandística y de prensa, o el desmesurado empleo de la simbología, tenían como claro objetivo reforzar esa adhesión activa y entusiasta, no solo con aquellos que formaban parte de la adhesión incondicional y providencial, sino también de aquellos colectivos más indecisos y de los que, con un tratamiento adecuado, podía obtenerse un apoyo fundamental en base a mostrarles la importancia de su papel en la Nueva España, a la vez que reforzar su visión polarizada y antagónica de las dos comunidades.

La construcción de la Comunidad de la Victoria necesitaba de una labor de integración que hiciera sentir a sus miembros que formaban parte activa y fundamental de un proceso palingenésico, y que ello les obligaba a permanecer movilizados y activos, aunque fuera en base a métodos claramente coercitivos, como los empleados por el alcalde de Antequera en agosto de 1936, y que arengaba a los vecinos a alistarse en el recién conformado Grupo de Voluntarios de la ciudad, señalando que "si usted no es emboscado, ni un canalla marxista con disfraz y aún no está en activo militando, inscríbase enseguida porque si no después tendrá usted que pasar la afrenta de ser llamado sinvergüenza, aprovechado y parásito profesional". ${ }^{27}$

\section{Consentimiento "Residual" y Asenso}

Después de los colectivos identificados como apoyos inquebrantables del Régimen, el proceso de construcción del resto de categorías resulta mucho más complejo hasta llegar a actitudes de resistencia y oposición abiertas -quizás en buena parte por el abuso de la polisemia en cuanto a los conceptos que los diferentes estudios han ido poniendo sobre la mesa de debate, y que desde luego no responden sino a la voluntad del historiador de querer dar cabida a toda esa multiplicidad de actitudes a las que no resultaba nada fácil dotar de un cuerpo homogéneo, perfectamente encuadrado. Sin embargo esta voluntad no siempre es garantía de éxito.

Por destacar un matiz, y que bien puede ser considerado como categoría de actitud, no siempre el apoyo de aquellos que se lo ofrecieron al Régimen fue necesariamente limpio y sin fisuras hacia algunas de sus administraciones periféricas, sino que también vino acompañado de discrepancias

\footnotetext{
25 Riquer, Borja de, "Rebuig, passivitat i suport. Actituds polítiques catalanes davant el primer franquisme (19391950)", Franquisme. Sobre Resistència i consens a Catalunya (1938-1959), Barcelona, 1990, p. 181.

${ }^{26}$ Saz, Ismael, Fascismo y franquismo..., op. cit., pp. 178-179 y 194.

${ }^{27}$ El Sol de Antequera. Antequera, 27 de septiembre de 1936, p. 3.
} 
puntuales, e incluso enfrentamientos abiertos, fundamentalmente entre Falange y las viejas oligarquías políticas.

Así son numerosos los casos en que se registran lo que hemos venido a definir como explosiones controladas, o resistencias afines, para referirnos a estos desencuentros establecidos entre grupos de incontestable apoyo al Régimen, que hemos encontrado para nuestra zona de estudio, como por ejemplo las protestas del comerciante antequerano, miembro de la Comisión de Festejos de este gremio, y responsable de la sección de Prensa y Propaganda de Falange, Luis Moreno Rivera, que criticaría públicamente algunas de las medidas, sobre todo en materia de Beneficencia y Asistencia Social, de la primera Gestora elegida tras la ocupación de la ciudad-compuesta en gran parte por gestores que ya desarrollaron responsabilidades políticas antes de la etapa republicana- como las relacionadas con la extinción de la mendicidad o las que sostenían la recaudación para el Plato Único. Precisamente sobre este hecho señala Moreno Rivera:

"No quiero imitar a la Comisión Gestora de nuestro Ayuntamiento, que deja incumplidos acuerdos por no evidenciarse con don fulano, por no disgustar a don zutano y por guardar consideraciones de respeto personal a quién no las merece... Antequera se porta bien unas veces y otras francamente mal. Ha contribuido con esplendidez a la suscripción para el Ejército, pero no está a la altura que su categoría exige en la suscripción para el Plato Único." ${ }^{28}$

Sin embargo nunca fueron actitudes que pudieran suponer un desarraigo del discurso franquista, y mucho menos una pérdida de adhesión al Régimen, sobre el que seguirían elaborando una lectura general muy positiva por encima de otras sombras, ${ }^{29}$ pero que sin embargo comenzaría a mitigarse de forma progresiva a medida que analizáramos actitudes cada vez más grises, menos entusiastas, y distanciadas de los planteamientos franquistas.

\section{Consentimiento Pasivo, Neutralidad, Indiferencia}

Ya ha sido planteado cómo, si bien una parte de la comunidad no desarrolló una adhesión entusiasta al Régimen, la pasividad generalizada que demostró, resultó de gran ayuda para su mantenimiento, ${ }^{30}$ ya que la inhibición de toda responsabilidad e implicación llevaría a una aceptación implícita o pasiva, ${ }^{31}$ a una "indiferencia acomodaticia", aunque lograra mutar en transgresión cuando fuera la subsistencia cotidiana lo que se ventilaba. ${ }^{33}$

Sin embargo la indiferencia al Régimen, como tendremos oportunidad de exponer más adelante, en una sociedad super-policial y auto-vigilada, era fiscalizada, incluso desde abajo, dependiendo de quién mostrara esa indiferencia, para ser condenada y denunciada, o por el contrario transigir con ella. ${ }^{34}$

El caso es que existen grupos sobre los que el alineamiento con el poder se vislumbra progresivamente más tenue, quizás más forzado, y desde luego más cercano a la indiferencia; una

${ }^{28}$ El Sol de Antequera, Antequera, 7 de marzo de 1937, pp. 1-2.

${ }^{29}$ De esta adhesión con divergencias nos habla Jordi Font en Font, Jordi, “-Nosotros no nos cuidábamos de la política-...", op. cit. El concepto de Asenso fue utilizado en primera instancia en Rodríguez, Óscar, "Miseria, consentimientos y disconformidades. Actitudes y prácticas de jóvenes y menores durante la posguerra", en Rodríguez, Óscar (coord.), El Franquismo desde los márgenes: campesinos, mujeres, delatores, menores..., Almería, Universidad de Almería y Universitat de Lleida, 2013, pp. 165-185

${ }^{30}$ Sevillano, "Consenso y violencia en el "nuevo estado" franquista...”, op. cit., pp. 161-162.

31 Rodríguez, "Cuando lleguen los amigos de Negrín... Resistencias cotidianas y opinión popular frente a la II Guerra Mundial. Almería, 1939, 1947”, Historia y Política, 18, 2007, p. 298.

${ }^{32}$ Font, Jordi, “-Nosotros no nos cuidábamos de la política-...”, op. cit., p. 52.

33 Rodríguez, Óscar, "Lazarillos del Caudillo. El hurto como arma de los débiles frente a la autarquía franquista", Historia Social, 72, 2012, p. 68.

${ }^{34}$ Parejo, José Antonio, “Fascismo rural, control social...", op. cit., pp. 143-159. 
actitud propia de aquellas zonas grises de la sociedad española de posguerra, que no se opusieron al Régimen en su establecimiento, pero que ni compartieron en profundidad ni participaron activamente de él, ${ }^{35}$ ni hicieron nada cuando terminó desmoronándose cuatro décadas más tarde. $^{36}$

Sin embargo esta Zona Gris no vivía aislada, de espaldas al resto de la sociedad, y mucho menos sus problemas le resultaban inocuos. Y decimos esto porque algunos trabajos ${ }^{37}$ han optado por situar a ésta como una categoría independiente entre las de consentimiento y oposición, al contrario de nuestra idea de integrarla dentro de actitudes de consentimiento y aceptación, o al menos de conformidad y acatamiento, pues partimos de la convicción de que cada individuo goza de una propia ideología, de un propio sentimiento, percepción y opinión ante a la actuación del Régimen, en base a una experiencia personal o a la propia interpretación discursiva, lo que incluía a estos moradores de las zonas grises, por lo que no consideramos adecuado aislarlas del resto de categorías, así se muestren cercanas al alineamiento o la disidencia.

Así por ejemplo algunos de los pequeños propietarios del pequeño anejo ${ }^{38}$ antequerano de Villanueva de Cauche, no mostraron reacción entusiástica hacia el Régimen, pero sí al menos su desacuerdo con la gestión económica y de abastecimiento de los comités en la retaguardia republicana. Era la impresión por ejemplo de Mariano Podadera, que señalaba:

"Nosotros no éramos ni de unos ni de otros, pero unos lo veían bien y otros malamente, porque el que nunca había tenido nada, ese lo veía bien, pero el que tenía algo como nosotros, como mi padre, pues esos lo veíamos malamente porque mi padre tenía las cámaras llenas de trigo y nos las barrieron" 39

Sea como fuere, y aunque de una forma más costosa y matizable, aún en ella sigue haciendo efecto el discurso legitimador y justificativo del Régimen, sobre todo en lo que supone asociar la República al caos y al recuerdo de la violencia en la retaguardia republicana.

Pero por encima del recuerdo de la violencia, comienza a primar el de olvido de la guerra, como forma de acomodamiento, de mutación progresiva desde la animadversión al consentimiento, en base a un principio de inacción y pasividad condescendiente. Paradójicamente, el Régimen que surgió de una sublevación hecha guerra, terminaría siendo el principal beneficiario del deseo mayoritario de una sociedad por olvidarse de ésta.

Autores como Alegre Lorenz -que a su vez sigue los planteamientos de otros como Hernández Burgos y Rodríguez Barreira- sostienen que una buena parte de la población, más que un apoyo decidido y entusiasta, desarrolló un acomodamiento al discurso y proyecto franquistas, lo que supondría situar las actuaciones mayoritarias en un plano de "participación inconsciente". 40 Sin embargo somos de la opinión de que no es esta una participación exclusivamente indeliberada, sino producto de variables que van desde el interés personal al miedo, el pragmatismo o la

\footnotetext{
${ }^{35}$ Sevillano, Francisco, “Consenso y violencia en el "nuevo estado" franquista...”, op. cit., pp. 159-171.

${ }^{36}$ Hernández, Claudio, Franquismo a ras de suelo. Zonas grises, apoyos sociales y actitudes durante la dictadura (1936-1976), Granada, Editorial Universidad de Granada, p. 7.

${ }^{37}$ Así por ejemplo Óscar Rodríguez Barreira en sus diferentes trabajos mencionados a lo largo de este texto.

${ }^{38}$ Se trata de una unidad poblacional inferior, dependiente de un municipio, aunque con Alcaldía propia. Para el caso argentino, podría por ejemplo establecerse un paralelismo con las pedanías en que se subdividen los departamentos que forman parte de la provincia de Córdoba.

39 Testimonio de Antonio Ruiz Muñoz (a) Ramiro. Villanueva de la Concepción. 29 de mayo de 2006.

40 Alegre, David, "Formas de participación y experiencia política durante el primer franquismo: la pugna por los principios ordenadores de la vida en comunidad durante el periodo de entreguerras (1936-1947)", Rúbrica contemporánea, V. 3, 5, 2014, p. 28.
} 
intranquilidad ${ }^{41}$, pero ya con un objetivo en el horizonte y sobre el que volveremos en este texto en más de una ocasión: la supervivencia. ${ }^{42}$

Así pues el deseo de superar el recuerdo de la guerra, de prosperar, o al menos de no sufrir en toda su crudeza los efectos de la dura etapa posbélica, así como de disipar dudas o huir de posibles acusaciones de tibieza, son algunos de los motivos que condicionarían esta categoría de relación entre Estado y una parte del pueblo, con una actitud más de no-oposición que de apoyo sin reservas, pero donde resultarían fundamentales acciones como la participación pública de ese nuevo escenario colectivo de exaltación a la recuperación de los valores tradicionales de España, o el incontestable apoyo a las iniciativas que implicaran suscripción económica.

$\mathrm{Y}$ es que el aspecto económico, si bien fundamental en todas las categorías, cobra en ésta una especial dimensión, a medida que la población comience a precisar de estrategias para que su posicionamiento no sea cuestionado, y el Régimen comience a valerse de ello.

La conversión de la sublevación en guerra trajo aparejado el sacrificio económico del pueblo, no solo como forma de costear en parte los gastos de su empresa guerrera, sino como vía que permitiera -obligara- a éste a una demostración exaltada de patriotismo en sus múltiples vertientes, en el sentido del agradecimiento por la salvación, de adhesión sin reservas como salvoconducto que permitiera el libre acceso a la España de los vencedores.

Por ello las suscripciones populares dieron la oportunidad al individuo de mostrar su comunión con el resto de la comunidad nacional de vencedores, de participar en un macroproyecto de movilización colectiva, y de dotar de una manifestación física y material el renacer de una nueva España sobre las cenizas de la antigua. Una Nueva España en la que se reconstruyen esplendorosamente los templos, resultado del remozado espíritu católico que ha inspirado la Cruzada, o donde se erigen igualmente monumentos de recuerdo y cohesión, de exaltación, y a la vez de recuerdo y reproche, castigo y apartamiento a los vencidos. Movilización vencedora y desmovilización vencida, coexisten por tanto, y tienen su reflejo en el aspecto económico.

Pero no siempre el entusiasmo fue el mismo, provocando la intervención de unas autoridades que, a través de una estrategia a partes iguales propagandística como disuasoria -por ejemplo a través de las listas públicas de morosos que no pagaran o no lo hicieran acorde a sus posibilidades económicas- desarrollarían actitudes coercitivas a medida que el entusiasmo inicial fuera degenerando hacia tácticas de evasión de una población a la que este "patriotismo caro",43 a través de las "extorsiones organizadas" 44 desde el Poder, estaba afectando seriamente su economía.

"La Alcaldía espera que nadie se excuse ni se retraiga porque será tachado de antipatriota y se expondrá a la censura de sus conciudadanos", 45 señalaba el alcalde de Antequera al observar cómo el ardor patriótico provocado tras la ocupación de la zona a mediados de agosto de 1936, había disminuido notablemente en pocos meses. Unas actitudes que algunos autores no tardarían en tipificar ya como manifestaciones de Resistencia, ${ }^{46}$ y que desde luego ya dejaban entrever una lejanía con toda actitud de consenso, a la vez que un control social más evidente.

\footnotetext{
${ }^{41}$ Cabana, Ana, "De imposible consenso...", op. cit., p. 89.

${ }^{42}$ Los comportamientos para la supervivencia, y su interrelación con otras actitudes ante el franquismo y sus violencias, tienen un reflejo inmejorable en obras como Mir, Conxita, Vivir es sobrevivir: justicia, orden y marginación en la Cataluña rural de posguerra, Lleida, Milenio, 2010 y Casanova, Julián (coord.), Morir, matar, sobrevivir. La violencia en la dictadura franquista, Barcelona, Crítica, 2002.

43 Melero, Miguel Ángel, “Vecinos armados y ‘parásitos’ grises...”, op. cit., pp. 173-199.

44 Preston, Paul, "La forja de un asesino: el general Queipo de Llano", en Anderson, Peter y Arco, Miguel Ángel del (eds.), Lidiando con el pasado..., op. cit., pp. 54-55.

45 El Sol de Antequera, Antequera, 8 de noviembre de 1936.

46 De hecho, Ana Cabana se refiere a estos comportamientos como de Resistencia Abierta, y en la que se incluirían variables que van desde el absentismo a la tibieza en actos públicos -homenajes, misas, enaltecimientos, desfiles...al intento de evadir la contribución económica en suscripciones populares -Plato Único, Auxilio Social, tómbolas,
} 


\section{Acatamiento realista y Resignación}

Efectivamente nos encontramos en pleno tránsito de una frontera peligrosa entre dos categorías de actitudes que muestran no pocos paralelismos: el deseo de olvido de la guerra, de prosperar en los diferentes ámbitos de la vida cotidiana, de erradicar dudas sobre una posible desafección huyendo de la tibieza, pero elevando en ésta la preocupación y la intranquilidad a la categoría de miedo por sus antecedentes políticos, ideológicos y sociales, como los de su entorno.

$\mathrm{Y}$ es que en ella se localiza una parte de la población en la que ciertamente puede llegar a confundirse su consideración de zona gris con otra que despierta dudas sobre su ascendencia republicana, y que lleva a favorecer necesariamente comportamientos de resignación y acatamiento.

Lo define de forma certera Ana Cabana cuando se refiere a ella como una actitud de "colaboración realismo", aunque disintamos de la autora gallega en la consideración que la misma hace de esta tipificación como una sub-categoría que denomina como de Consentimiento por coerción, por no encontrar en ella ya las bases mínimas para la aplicación de un consenso. ${ }^{47}$ Por ello consideramos como más adecuada una categorización en base al Acatamiento.

En todo caso el Régimen comienza a verter sobre esta parte de la comunidad un uso que entiende como moderado del control social en base a la intranquilidad y el miedo, y a través de un país auto-vigilado en el que resultaría fundamental la participación ciudadana, convertida en ocasional policía a través de la delación. ${ }^{48}$

Pero es este un señalamiento que no solo proviene de los afines, sino que, de forma paradójica y como consecuencia de una coyuntura de excepcionalidad que genera la hiperbolización de los enfrentamientos y los antagonismos a través de una guerra fratricida, se localizan naturalezas alteradas y comportamientos distorsionados de aquellos que pueden llegar a desarrollar acciones de colaboración en el proceso represivo a partir del señalamiento de sospechosos ante un Estado franquista ávido de recibir denuncias, como de ejecutarlas.

Unas denuncias que en esta categoría ya no se encuadran en un contexto de venganza por sufrimientos pasados, o como pasaporte para una entrada en la comunidad de vencedores, sino como forma de huir de la consideración de tibieza, por miedo o por supervivencia, y donde desde luego resultaba fundamental el grado de presión que sobre éstos establecieran los mecanismos coercitivos del Estado. ${ }^{49}$

Así por ejemplo fueron numerosos los casos en que vecinos de Villanueva de Cauche que habían huido de este anejo ante la ocupación sublevada del mismo en febrero de 1937, y que fueron detenidos y encausados por la justicia militar franquista tras el final de la guerra, terminaron siendo absueltos o sobreseídos sus casos, no sin antes señalar a los "verdaderos culpables" actos de violencia desarrollados en el anejo durante la retaguardia republicana. Siempre los mismos nombres, y siempre en el mismo orden en los procesos, lo que nos lleva a reflexionar

donativos, ayuda a combatientes, excombatientes y mutilados, homenajes, estatuas, regalos...-. Cabana, Ana, La derrota de lo épico, Valencia, Universitat de València. Servei de Publicacions, 2013, pp. 282 y ss.

${ }^{47}$ Cabana, Ana, "De imposible consenso...", op. cit., p. 94.

48 Carlos Gil establece, para la participación ciudadana en la represión, una distinción entre directores, ejecutores, intercesores y colaboradores. Gil, Carlos, “También 'hombres del pueblo'. Colaboración ciudadana en la gran represión”, en Arco, Miguel Ángel del et al. (coords.), No solo miedo..., op. cit., pp. 51 y 63, y sobre la que realizamos un análisis crítico en Melero, Miguel Ángel, De la Esperanza..., op. cit. De la misma forma, un análisis profundo sobre todo ello en nuestra comunicación "Un proceso poliédrico: nuevos enfoques sobre las actitudes ante la represión franquista", y defendida en el Congreso "Posguerras: 75 aniversario de la guerra civil española”, Madrid, abril de 2014.

49 Supuestos que ya hemos señalado no recoge Francisco Cobo Romero. Cobo, Francisco, "Acerca de los iniciales apoyos sociales prestados al Franquismo...", op. cit., pp. 39-40.

${ }^{50}$ Causas 1354-1363/1939 (Archivo del Juzgado Togado Militar No 24 de Málaga). 
sobre el grado de presión al que pudieron ser sometidos los encartados para cambiar delación por libertad, y establecer paralelamente una plantilla de señalados.

Efectivamente, las actitudes de la población pudieron variar y redefinirse ante una guerra que lo cambió todo, en base a variables que podían ir desde esta presión a cambio de supervivencia al interés personal y reditual, -así por ejemplo, el aprovechamiento por la política autárquica franquista-. Por tanto, actitudes cambiantes que coexistirían con otras que, lejos de variar, se reafirmarían y radicalizarían en un contexto de convulsión, o con aquellas que, simplemente, quedaron minimizadas hacia espacios cada vez más acotados y ajenos al control directo. ${ }^{51}$

\section{Aversión, Resistencia “interior" y cotidiana, Resiliencia y Pragmatismo para la supervivencia}

Estos comportamientos cambiantes pudieron ser propios de aquella población que se sentía más perseguida que policía, y que centró su escasa libertad de movimiento en buscar con ansia un camino hacia la normalidad, hacia la recuperación de unos parámetros mínimos que no iban más allá del círculo familiar o de amistades más íntimas, y aunque ello supusiera el cerco a su ámbito de actuación y autonomía, a su desmovilización y aislamiento; a su despolitización, al encierro en la esfera privada y al desinterés por el entorno. ${ }^{52}$

Este arrinconamiento parecía ser el precio a pagar por parte de esta parte de la comunidad a cambio de la supervivencia física, e incluso la moral y anímica. Una actitud realista de una población que, ante la coyuntura que se le plantea, no encuentra alternativa, iniciando una adaptación de aspiración a la realidad, con el objetivo de alcanzar una mínima armonía que pudiera combatir en parte el cercano aliento del terror cotidiano. ${ }^{53}$

En una coyuntura en la que el Régimen criminalizaba tan abiertamente el pasado republicano, la necesidad de supervivencia del que se encontraba en entredicho superaba cualquier afán de disensión, obligando a éste a comportamientos externos resilientes, de adaptación, de alteración y engaño, mientras que la auténtica libertad quedaba, en el mejor de los casos, al amparo de esos espacios privados cada vez más acotados, aquellos donde la verdadera identidad política y social del vigilado podía vislumbrarse,$^{54}$ aún de forma muy discreta, y donde podría desarrollar sus más intimos mecanismos de resistencia "interior" ${ }^{25} \mathrm{O}$ "micropolítica subalterna" ${ }^{56}$ frente al franquismo, a sus preceptos, sus métodos y su violencia.

La frontera que separaba la aceptación, en sus diferentes grados y por distintas motivaciones, de la disidencia, había sido traspasada y en ella dudosos de antecedentes republicanos, represaliados en sus diferentes manifestaciones, incluidos aquellos que, a pesar de no encontrarse cumpliendo condenas de cárcel, habían asimilado el escarnio y el vituperio como algo natural y cotidiano -por ejemplo los que podrían encuadrarse como integrantes de una comunidad represaliada, es decir, la familia o el entorno de los asesinados o encarcelados, de los depurados laboralmente o de los

\footnotetext{
${ }^{51}$ Sevillano, Francisco "Consenso y violencia en el "nuevo estado" franquista...", op. cit., p. 170.

52 Font, Jordi, “-Nosotros no nos cuidábamos de la política-..., op. cit., pp. 49-66.

${ }^{53}$ Cabana, Ana, "De imposible consenso...", op. cit., pp. 89-106.

${ }^{54}$ Míguez, Antonio, "La naturaleza 'no política' del franquismo. Adaptación social y resiliencia”, en Fernández, Lourenzo y Artiaga, Aurora (eds.), Otras miradas sobre golpe, guerra y dictadura, Madrid, La Catarata, pp. 179-200.

55 Un sentido muy similar fue el aplicado por Ximena Machado a la hora de abordar el concepto de la "resistencia pasiva", al referirse al comportamiento de los judíos confinados en los guetos polacos de Lodz y Varsovia, en el contexto de ocupación alemana de Polonia, y de cómo su única reacción ante la represión y la muerte consiste en su casi obsesivo objetivo de pervivencia de su legado y esencia culturales, muy por encima de la salvación física. Lo hizo en su comunicación "¿Cómo ovejas al matadero? Formas de resistencia pasiva de los judíos en los guetos de Varsovia y de Lodz (1939-1942)”, IV Encuentro de Jóvenes Investigadores en Historia Contemporánea, Valencia, septiembre de 2013.

56 Rodríguez, Óscar, "Lazarillos del Caudillo...”, op. cit., p. 86.
} 
mancillados económica y patrimonialmente, y víctimas de una represión cotidiana y de abajo hacia abajo, o de aquellos sobre los que de forma masiva llegó a ejercerse la caridad y la asistencia social como estrategia de amilanamiento y control social ${ }^{57}$ - constituían todos una afiliación a esa antiEspaña vencida que, siquiera de forma privada, pero con un extrema cautela, muestra su aversión y oposición al Régimen, producto de la represión sufrida por su antagonismo ideológico y político.

Pero ¿cómo transcurre la vida diaria de este parte de la comunidad? Y, sobre todo, ¿cuáles son las estrategias de desarrollo de la resistencia cotidiana que emplea?

Son, con casi con toda seguridad, los estudios desarrollados en torno al concepto y actitudes de resistencia, y muy especialmente los que James $S \operatorname{cott}^{58}$ ha tipificado como resistencia cotidiana, los más prolijos y actualizados hasta la fecha en cuanto al análisis de las actitudes ante la dictadura franquista, gracias al redimensionamiento que de ellos hace Ana Cabana en su escrupuloso retrato del comportamiento de la comunidad rural gallega ante el establecimiento del Régimen y su desarrollo durante sus dos primeras décadas. ${ }^{59}$

El franquismo preconizó tras la guerra, gracias entre otras cosas a un aparato mediático y propagandístico muy potente, el establecimiento de una verdadera y duradera Pą. Social, pero que para muchos no supondría sino una ficción, a partir de la imposición y la represión, de lo que era su idea de Estado, generando con ello un sentimiento cuanto menos de resignación entre una buena parte de la comunidad; un mito por otra parte derribado gracias a la proliferación de estudios que desde hace algunos años han venido situando su atención en el análisis de las resistencias cotidianas ante el nuevo poder.

Existió efectivamente una resistencia, en algunos casos puntual y aislada, de aquellos que incluso sin haber luchado contra la sublevación, se sintieron desfavorecidos. Una resistencia cotidiana que pasaba a ser considerada, no como una opción de oposición organizada y grupal frente al poder dominador, sino como otra más individualizada, menos llamativa, residente en acciones y comportamientos diarios, que surgía como estrategia de defensa y contestación como alternativa a la expresión libre, abierta, colectiva y organizada que no era posible en un contexto de poder dictatorial, alto sometimiento y fuerte represión, sobre todo en los primeros años del Régimen.

Se trataba de una oposición sigilosa en muchos casos, que podía llegar a mermar al dominador, y sobre la que el propio Scott afirmaba que no tendría como finalidad provocar grandes cambios en el sistema de dominio contra el que actúa.

Sin embargo desde nuestra postura entendemos que sí pudieron llegar a pretenderse deseos de cambios, de derrocamiento, pero faltó el potencial suficiente para llevarlos a la realidad, quedando por el contrario, minimizados en lo que hemos venido a denominar como una resistencia-resignación.

Fue el caso de Andrés Lozano, que permanecería en prisión entre 1939 y 1943 por un delito de Rebelión militar y que, aún estrechamente vigilado y reducido al máximo su espacio de libertad tras su encarcelamiento, trabajaría activamente, aunque con resultado infructuoso, en el proceso de reconstrucción del Comité Comunista Antequerano "Troika", siendo denunciado y detenido, y de nuevo condenado y enviado a una prisión de la que no saldría en este caso hasta diecinueve años más tarde. ${ }^{60}$

\footnotetext{
57 De esta estrategia encubierta de control social se habla en Rodríguez, Óscar, "Auxilio Social y las actitudes cotidianas en los Años del Hambre, 1937-1943", Historia del Presente, 17, 2011, p. 128, por ejemplo de cómo la necesidad puede llevar a la Resiliencia, para obtener asistencia, pero generando a su vez un nuevo rechazo cuando los no-convencidos del Franquismo capten que las políticas sociales del Régimen, a pesar de mostrarse rodeadas de una potente propaganda, apenas si palian la situación de extrema miseria en que viven, pero contribuyen en cambio a potenciar el control social.

${ }^{58}$ Scott, James, Weapons of the week: Every day forms of peasant resistance, New Haven, Yale University Press, 1985.

${ }^{59}$ Cabana, Ana, La derrota..., op. cit.

${ }^{60}$ Melero, Miguel Ángel, De la Esperanza al Sometimiento..., op. cit.
} 
Esta resistencia interior llevaría aparejada igualmente una actitud resiliente, combinando la realidad privada con una figuración entusiástica, pública y propagandística, y que nos lleva a plantearnos cuestiones como si la denominada como Comunidad de vencedores no constituía en realidad un eufemismo que no pasaba de ser un artificio de búsqueda de cohesión, o si la tan renombrada adhesión al franquismo no era más que una mera representación para la propaganda y el establecimiento de un imaginario colectivo, promovido desde el Régimen, y por otro lado poco acorde con la realidad.

Por ello no resulta extraño que nos asalten no pocas dudas sobre la viabilidad de unos comportamientos de los que desconocemos la efectividad que puede tener una oposición pasiva en base a la resistencia privada y escondida, más allá del fin catártico, de desahogo mental, de refugio para la resignación o de superación personal, psicológica, del sometido frente al opresor, a sabiendas de que este rol no podía ser revertido, dada la imposibilidad de una demostración física de resistencia por parte de los vencidos y desafectos, por el miedo, la paralización y el apartamiento que este Régimen represor les proporcionaba, como la auto-represión impuesta a través del silencio que se conferían a sí mismos como única vía para sobrevivir.

En todo caso lo que nos queda claro es de que, si bien la resistencia cotidiana no es la única opción, sí que en un contexto de absoluta represión como la inmediata posguerra la entendemos como la más viable, si el objetivo final es la supervivencia, y de paso reafirma la cultura solidaria de grupo al que se pertenece.

$\mathrm{Y}$ es que no cabe duda de que "son las estrategias de supervivencia las que sirven de línea de fractura de la resistencia", de la misma forma que "la resistencia civil fue una fórmula escondida habitualmente en estrategias de supervivencia para el común de la población”, binomio supervivencia/resistencia se plantea obligatoriamente indisoluble para nuestro objeto de estudio.

Por ejemplo, establece Óscar Rodríguez una categoría que en base a la esencia que el autor nos plantea, podríamos denominar como de resistencia económica cotidiana, ${ }^{62}$ y que establece como una ramificación de las actitudes de resistencia como consecuencia de una política autárquica. De la misma forma, el mismo autor señala en otro de sus trabajos que ciertas formas de hurto pudieron constituir formas encubiertas de resistencia al franquismo. ${ }^{63}$

Sin embargo, y a pesar de que en un régimen totalitario cualquier acción contraria a las férreas disposiciones impuestas es entendida como subversiva, entendemos que prácticas como el mercadeo negro, el estraperlo o el hurto no son solo resultado de actitudes de resistencia, sino aplicables a más de una categoría, cada una de ellas con diferente intensidad, motivación y resultado: lucro por parte de los que, aprovechando su apoyo incondicional al Régimen, se enriquezcan en estas acciones contando además con una permisividad por parte del Poder; aprovechamiento de los que, aún con una relación recíproca de menor confianza con el Nuevo Estado, encuentren también cierta permisividad, y supervivencia de aquellos que a la persecución y el apartamiento debieron sumar una situación de extrema miseria.

No suponía por ejemplo lo mismo el hecho de que un falangista antequerano que había permanecido durante la guerra convaleciente en un hospital, fuera descubierto al robar mantas en el mismo para posteriormente lucrarse vendiéndolas, a que un pobre jornalero del también anejo antequerano de Bobadilla, Francisco Ramos, señalara que "como no tenía nada que comer, y estaba desesperado, me dediqué al estraperlo". ${ }^{64}$

\footnotetext{
${ }^{61}$ Cabana, Ana, La derrota..., op. cit., pp. 147 y 282.

${ }^{62}$ Rodríguez, Óscar, “Auxilio Social y las actitudes cotidianas...”, op. cit., pp. 133 y 145.

${ }^{63}$ Rodríguez, Óscar, "Lazarillos del Caudillo...", op. cit., p. 66.

${ }^{64}$ Testimonio de Francisco Ramos del Pozo, Bobadilla, 17 de mayo de 2006.
} 
Sea como fuere, los mecanismos del Régimen permitían incluso que beneficiarios y víctimas de sus medidas coincidieran a veces en acciones similares, pero cuyas naturalezas y motivaciones les impedían ser tipificadas como actitudes de resistencia, al menos no conscientes.

En un contexto en el que prima la ecuación de que a más violencia y represión y más criminalización de la vida cotidiana, menos contestación, más subordinación y mayor eficacia de la estrategia desmovilizadora franquista, la supervivencia del individuo y su entorno -su autoconservación - es lo primero, aunque ello implique modificar los "limites de seguridad" para mostrar disenso y disconformidad. ${ }^{65}$

Este hecho ha motivado otro intenso debate en relación a las distinciones que podrían establecerse entre las categorías de resistencia y oposición, conceptos que entendemos como perfectamente combinables, como por el ejemplo en el caso de la resistencia guerrillera antifranquista, ya que el resto de vencidos, sometidos, no disponen de la opción de señalarse ni ser señalados, sin traer aparejada una represión segura y mortal, una pérdida de la libertad, o la imposibilidad de una prosperidad económica.

\section{El Reproche y la Solidaridad como formas de resistencia y la Oposición Intermedia}

Pero ¿hasta qué punto resistencia y oposición representan actitudes diferenciables? Algunos de los autores aquí mencionados establecen una distinción entre ambas categorías, aunque no coinciden en la jerarquía que debe situar a una u otra.

Así por ejemplo Rodríguez Barreira establece la Oposición con la categorización más intensa dentro de la disconformidad, y en la que la más tibia correspondería a la resistencia. Igualmente Cabana otorga a la Oposición una sublimación que no contempla para la otra categoría, al señalar que no hay nada de épico en la resistencia civil, por tratarse de "un conjunto de circunstancias puntuales y de las capacidades relacionadas de los individuos", mientras que "la oposición si lo fue". 66

Por el contrario, consideramos matizables algunas de estas reflexiones, por entender que la oposición, en caso de aceptar una distinción entre ambas categorías, también podría estar sometida y condicionada por coyunturas y capacidades específicas; de la misma forma que la resistencia también podría lucir un halo de épica, teniendo en cuenta lo que sus ejecutores pudieran arriesgar en un régimen de tanta violencia y represión.

Otra cosa es que se desarrollara una actitud que hemos considerado definir como de Pragmatismo para la supervivencia, y que debía aparecer condicionada por el cálculo de "ganancias" y "pérdidas" que pudieran acarrear las acciones de resistencia para los que las llevaran a cabo, aunque desde luego también influirá la mayor o menor permisividad de un Régimen que también necesita emplear márgenes de tolerancia, necesarios para su propia perdurabilidad, por ejemplo con la Segunda Guerra Mundial como punto de inflexión, pero también a niveles más inmediatos, con la condescendencia en algunos casos de las autoridades locales franquistas a la hora de permitir ciertos actos de disenso y resistencia, o incluso aquellos comportamientos que suponían aprovechar las ya consabidas fricciones que se dieron entra autoridades, por ejemplo entre alcaldes y jefes locales de Falange, resultado fundamentalmente de las discrepancias entre las diferentes instituciones por el control de los recursos y el poder político, en un contexto excepcional. ${ }^{67}$

\footnotetext{
${ }^{65}$ Cabana, Ana, La derrota..., op. cit., pp. 19, 22, 23, 25, 37, 48 y 78.

${ }^{66}$ Cabana, Ana, La derrota..., op. cit., p. 282.

${ }^{67}$ Cabana, Ana, La derrota..., op. cit., pp. 63 y 68. Varios casos también en Melero, Miguel Ángel, De la Esperanza..., op. cit.
} 
No sabemos ciertamente qué tipo de cálculo de ganancias y pérdidas realizaron los protagonistas de algunos de los ejemplos que seguidamente plasmamos, ni si pensaron en la heroicidad o no de sus actos.

Incluso algunos se dejaron llevar por la valentía embriagadora de alguna bebida alcohólica, como señala Ana Cabana para el caso del agro gallego, u Óscar Rodríguez, cuando afirma que "la vinculación entre los comentarios contra el Régimen y el alcohol no era infrecuente", pero que en todo caso podemos corroborar para nuestros estudios sobre la comarca antequerana, apareciendo como frecuente el estado de embriaguez como motivador en la comisión de estas acciones, lo que de forma paralela otorgaba al Régimen una nueva estrategia de discurso sustentada en la idea de mostrar que nadie en su sano juicio o con sus facultades en orden, sería capaz de llegar a insultar al Régimen, verter sobre él máximas derrotistas y rumores, o incluso realizar cualquier tipo de broma o chascarrillo. ${ }^{68}$

Por ejemplo Ramón Arcas, vendedor ambulante antequerano, fue condenado en 1941 a una pena de seis años y un día, acusado de derrotismo por comentar a un grupo de trabajadores que varias ciudades se habían sublevado contra el Régimen, y que "el 2 de mayo banderas republicanas llenarían las calles de Antequera"."

Pero incluso en los regímenes más coercitivos, existía un margen de maniobra para el dominado, ${ }^{70}$ y la resistencia traspasó en ocasiones, de forma sobria y no carente de épica, su cada vez más cercado espacio de ejecución, y quizás por la valentía que solo emana cuando todo parece haberse perdido, las actitudes de una parte de la población hacia el Régimen que había frustrado sus esperanzas y probablemente había acabado con la vida, la libertad o el dinero de los suyos, también se midieron en un nivel que, sin llegar a un grado de oposición activa, tampoco se limitaron a un sometimiento silencioso, sino que se centraron en lo que hemos denominado como Oposición intermedia, con los vencidos y represaliados cotidianos -donde el entorno familiar desempeña un papel primordial- de nuevo como protagonistas que muestran su rechazo, no solo ideológico sino también por el daño sufrido por la acción represora, y que utilizan la vía del reproche para su exteriorización, como canal de comunicación directa con los participantes en primera persona en la acción represora - un cabo de la Guardia Civil de un cuartelillo de pueblo, el Teniente de un Batallón de Trabajadores, o los vecinos mismos del municipio que participaron como agentes de la represión en un asesinato, ya fuera como delatores o como miembros del piquete de fusilamiento improvisado-.

No es desde luego una actitud muy frecuente, sobre todo en los primeros compases del franquismo en los que ésta podría llevar a un recrudecimiento de la acción represora sobre uno mismo como sobre el entorno, pero en todo caso existe, como lo demuestran algunos testimonios, por ofrecer precisamente una visión distinta a la del acatamiento ante la injusticia franquista, y mostrar una interesante nueva vía en la manera en que se desarrollaron las relaciones entre vencedores y vencidos o represaliados, en sus diferentes grados.

Así por ejemplo, José Pacheco, del municipio malagueño de Humilladero, recuerda:

"Una tarde mi patrón me mandó ir a llevar un cheque a la estación en una bicicleta que él mismo me dio. Al volver me denunciaron los civiles y el civil y me dijo -La denuncia tienes que pagarla tú-. -Yo no la pago porque yo ya terminé mi jornal y fue un favor que yo le hice al patrón-, le contesté. -Pues como no la pagues verás- y soltó un vergajazo en la

\footnotetext{
${ }^{68}$ Melero, Miguel Ángel, De la Esperan₹a..., op. cit. RODRIGUEZ BARREIRA, Óscar, "Cuando lleguen los amigos de Negrín...", op. cit., 315.

${ }^{69}$ Causa 5607/1942. (Archivo del Juzgado Togado Militar No24 de Málaga)

${ }^{70}$ Font, Jordi, “-Nosotros no nos cuidábamos de la política-..., op. cit., 53.
} 
mesa. -A mí no me asustan los vergajazos, yo ya he pasado mucho... y de ti tampoco me asusto-, le contesté". ${ }^{71}$

Tampoco debió quedar exenta de riesgo la actitud de una mujer bobadillense, de la que nos dice su hija que "mi madre lo único que tenía es que le fue diciendo a cada uno lo que le tenía que decir, de los que habían matado a mi padre, a todos, ella era de las que pasaban por la vera del criminal de su marido y se lo decía en la cara... y ellos no decían nada, callarse". ${ }^{72}$

Y desde luego llamativo por lo desafiante fue el enfrentamiento del prisionero natural de Villanueva de la Concepción, Andrés Núñez, con un Teniente responsable en un batallón de trabajadores, cuando recuerda el protagonista:

"Discutí con el Teniente, que era un sinvergüenza. Me llamó el tío -desgraciado-. Entonces pegué un salto y le dije -Mi Teniente, esa palabra no se la consiento ni a mi padre, jrepítala usted!- No la repitió... ¡Me cago en la madre que lo parió!, decirme desgraciado, ique en esa palabra entra todo!... me la jugué....733.

Eran desde luego éstas actitudes, si bien no ya tanto de oposición directa al Régimen franquista, sí a la actuación, en un plano inmediato, de los que bajo éste actuaban, como autoridades en el mismo, agentes de la represión, y beneficiarios en general.

Igualmente épico fue en ocasiones también el papel desarrollado por aquellos que, aunque anulados políticamente, transgredieron las leyes franquistas al proteger unas prácticas delictivas el hurto y los delitos contra la propiedad-con una finalidad de supervivencia, resultado de una pobreza de nuevo cuño por la más absoluta miseria provocada por las medidas económicas del Régimen, y frente a las que éste mostraría señales inequívocas de incapacidad, impotencia e incompetencia, por aplicar a estos delitos comunes la misma Justicia militar que empleara frente a los políticos; o quizás se tratara de una nueva señal de un Poder que situaba cualquier delito como un acto subversivo frente a los preceptos del Nuevo Estado.

En ellos, como por ejemplo en los que actuaron como enlaces de la guerrilla antifranquista, aflora una oposición intermedia, pero en la que desde luego prevalecen comportamientos de supervivencia y solidaridad, aunque efectivamente pudieran generar también lo que podríamos denominar como resistencia no-consciente o no-buscada, es decir, aquella que no persigue subvertir nada de forma consciente, aunque le sea ajeno, sino sobre todo consolidar y reforzar lo propio, como manera de optimizar la acción en sus restringidos espacios. Resistencias individuales pero sustentadas en nociones morales compartidas, de reforzamiento de la identidad de grupo. ${ }^{74}$ Una visión en definitiva, del nosotros frente al ellos, vista desde la otra orilla.

No hace falta hablar de la importancia del apoyo económico, material y moral que los enlaces proporcionaron a los guerrilleros de la sierra, pero no cabe duda de que la afinidad por lazos familiares o de amistad, de vecindad, ideología y política, con una más que probable situación económica y social similar, nos lleva a afirmar la existencia de una resistencia por analogía, de ayuda solidaria por la similitud de las condiciones.

Por ello resulta lógico que los guerrilleros solieran actuar cerca de sus lugares de origen, amparados por sus redes de apoyo, y por eso resultará también tan decisivo que, en una coyuntura de recrudecimiento de la lucha contra el maquis, lo más eficaz para precipitar su caída fuera torpedear la línea de flotación de sus enlaces.

\footnotetext{
71 Testimonio de José Pacheco Tejada, Humilladero, 13 de marzo de 2006.

72 Testimonio de Carmen Jiménez Hidalgo, Bobadilla, 17 de mayo de 2006.

${ }^{73}$ Testimonio de Andrés Núñez Aranda, Pasteleros, 29 de mayo de 2006.

${ }^{74}$ Rodríguez, Óscar "Lazarillos del Caudillo...”, op. cit., p. 66.
} 
De nuevo la ecuación de a más violencia y represión menos capacidad de resistencia, funcionaba, encontrando una conclusión común a ambas: la represión como la resistencia apartaron a unos y heroizaron a otros.

En todo caso la actitud más cercana a la de oposición activa de aquellos otros vencidos y represaliados que, en sus muy reducidos espacios de libertad vigilada, desde la clandestinidad en el interior de las cárceles, o a través del fenómeno maqui, protagonizaron un claro rechazo al franquismo, con un pertinaz objetivo de conseguir su derrocamiento, en este último caso, radical y público, y que desde luego generará, hasta su erradicación a principios de la década de los Cincuenta del siglo pasado, graves problemas de estabilidad en un Régimen que volvía a valerse de la misma estrategia que ya empleara contra la República: demonización y brutalización del enemigo, en este caso en la equiparación de la lucha guerrillera antifranquista con el bandidaje, la delincuencia común y el terrorismo. ${ }^{75}$

Los guerrilleros antifranquistas buscaron sus espacios de resistencia en el monte, a la espera de coyunturas favorables que nunca llegaron a darse, y aún así, en una coyuntura de recrudecimiento definitivo de la lucha contra el maquis, sobre todo a través del eficaz uso de los antes guerrilleros y ahora delatores y miembros de las contrapartidas junto a la Guardia Civil, se constatan actitudes de resistencia y oposición activa, definitivas, trascendentales y no exentas de un añadido de épica y herencia moral frente a la dictadura: el suicidio como forma de procurar que otros espacios de resistencia, aunque pequeños, pudieran seguir manteniéndose y proliferando.

Pero ni tan siquiera dispusieron de espacios, por mínimos que estos fueran, para poder desarrollarse: los prisioneros, los depurados laboralmente, los represaliados económica y patrimonialmente, los desterrados o en libertad vigilada.

Aquellos a los que la asfixiante política represiva estructural que había completado la desarticulación de sus partidos y sindicatos, el descabezamiento de sus líderes, y la deconstrucción de su cultura política obrera, les llevó a un silencio con el que olvidar su consideración de vencidos, a experimentar un alejamiento, incluso íntimo, de toda preocupación política, y a desarrollar una renuncia explícita a su pasado republicano como último reducto para la definitiva aniquilación de su memoria. ${ }^{76}$

No existió consenso ni consentimiento para ellos; ni estrategias de negociación ni de incorporación a comunidades de vencedores, ni zonas grises. Y mucho menos posibilidades de indiferencia o disidencia. Solo desarraigo, desmovilización, pérdida de la identidad política y social, sometimiento, silencio y miedo. Y los muertos, ni eso.

\footnotetext{
75 Sobre ello reflexionamos a la hora de analizar el alcance de la represión sobre la resistencia guerrillera antifranquista en Andalucía en nuestro trabajo, de inminente publicación, "La represión franquista sobre la resistencia guerrillera en Andalucía. Un balance actualizado", de la misma forma que así se menciona en Marco, Jorge, Guerrilleros y vecinos en armas. Identidades y culturas de la resistencia antifranquista, Granada, Comares, 2012.

76 Rodríguez, Óscar, "Cuando lleguen los amigos de Negrín...”, op. cit., 299; SAZ CAMPOS, Ismael, Fascismo y franquismo..., op. cit., 178.
} 